\title{
Effect of Wrist Tapping on Interhemispheric Coherence in Patients with Juvenile Myoclonic Epilepsy
}

\author{
Ekaterina A. Narodova, $\mathrm{PhD}^{1^{*}}$; Natalia A. Shnayder, $\mathrm{PhD}, \mathrm{ScD}^{1,2}$; Vladislav E. Karnaukhov ${ }^{1}$; \\ Olesya D. Bogomolova ${ }^{3}$; Kirill V. Petrov ${ }^{1}$; Valeriya V. Narodova, $\mathrm{PhD}, \mathrm{ScD}^{1}$ \\ ${ }^{1}$ V.F. Voino-Yasenetsky Krasnoyarsk State Medical University, Krasnoyarsk, Russia \\ ${ }^{2}$ V.M. Bekhterev National Medical Research Center of Psychiatry and Neurology, St. Petersburg, Russia \\ ${ }^{3}$ Medical Center "Health Compass", Krasnoyarsk, Russia
}

\begin{abstract}
The aim of this study was to assess the dynamics of interhemispheric coherence (IC) as an indicator of integration of different areas of the brain and their participation in the performance of certain functions before and after wrist tapping (WT), using the author's method in juvenile myoclonic epilepsy (JME).

Methods and Results: The study included 81 subjects of working age, including 51 clinically healthy volunteers (median age of 39[21;56] years) and 30 patients (median age of 27[23;38] years) with JME. Analysis of IC in the electrode pairs Fp1Fp2, F3-F4, C3-C4, T3-T4 was performed using a computer encephalographic complex. A coherent EEG analysis was used to identify and evaluate the relationships between different areas of the brain. Based on the change in the coherence coefficients (CCs), the level of integrative activity of brain structures was quantified. In healthy volunteers, before and after WT, we observed a statistically significant decrease in CCs for the beta-1 band in the pairs Fp1-Fp2, F3-F4, and C3-C4 $(P<0.05)$, while in the pair T3-T4, changes in CCs were not statistically significant $(P>0.05)$. At the same time, a statistically significant decrease in CCs in the alpha band was found only in the frontal regions in the pairs Fp1-Fp2 and F3-F4 $(P<0.05)$. No statistically significant changes were found in all the studied pairs in the theta band. When comparing CCs in JME patients in beta-1 and theta bands, before and after WT, we did not find statistically significant changes in CCs in all the studied electrode pairs. However, in the alpha band, we found a statistically significant decrease in $\mathrm{CCs}$ in the frontal region in the $\mathrm{F} 3-\mathrm{F} 4(P=0.0038)$ and $\mathrm{C} 3-\mathrm{C} 4$ electrode pairs $(P=0.034)$. The results of the study of interhemispheric integration showed statistically significant differences between patients with JME and the control group.

Conclusion: WT according to the author's method does not provoke the occurrence of interictal epileptiform discharges on the EEG and epileptic seizures in patients with JME. Coherent analysis showed positive changes in interhemispheric integrations of neurons in the beta-1 and alpha frequency ranges, mainly in the anterior hemispheres. (International Journal of Biomedicine. 2021;11(1):73-77.)
\end{abstract}

Key Words: interhemispheric coherence $\bullet$ electroencephalography $\bullet$ epilepsy $\bullet$ wrist tapping

For citation: Narodova EA, Shnayder NA, Karnaukhov VE, Bogomolova OD, Petrov KV, Narodova VV. Effect of Wrist Tapping on Interhemispheric Coherence in Patients with Juvenile Myoclonic EpilepsyInternational Journal of Biomedicine. 2021;11(1):7377. doi:10.21103/Article11(1)_OA12

\section{Introduction}

The pathogenesis of epilepsy is based on the spontaneous membrane instability of neurons, which leads to the appearance of a paroxysmal depolarization shift on the cell membrane.

*Corresponding author: Ekaterina A. Narodova, PhD. V.F. Voino-Yasenetsky Krasnoyarsk State Medical University, Krasnoyarsk, the Russian Federation. E-mail: katyan2001@mail.ru
In this case, a sudden prolonged depolarization of the neuron occurs with the resulting flash of discharges. The increased tendency to depolarization of epileptogenic neurons is due to their so-called hypersensitivity caused by damage to the membrane or neuron metabolism: violation of the regulation of the concentration of extracellular ions and (or) transmitters that determine their imbalance. The latter leads to increased excitability of neural networks due to a lack of inhibitory effects. ${ }^{(1)}$ However, an epileptic focus is not yet epilepsy, 
since in the presence of an electrographically recorded focus, an epileptic attack may be absent, and the disease does not develop. On the other hand, even with clinically manifest epilepsy, epileptic seizures are repeated, as a rule, only with a certain frequency; therefore, in the pauses between them, the epileptic focus remains blocked. In patients with juvenile myoclonic epilepsy (JME), functional disconnections in thalamo-motor and thalamo-frontal networks were found. ${ }^{(2,3)}$ According to the study performed by Y.Wang, ${ }^{(4)}$ functional network activity at rest was shown to be higher in JME patients in several brain regions than in healthy volunteers. At the same time, the brain regions involved in primi hyperfunction are mostly located in the left hemisphere, including the dorsolateral prefrontal cortex, the middle temporal gyrus, and the dorsal part of the striatum. Patients with JME had not only higher average values of indicators over the entire study period, but also a higher level of their variations, as evidenced by standard deviations of time series.

The aim of this study was to assess the dynamics of interhemispheric coherence (IC) as an indicator of integration of different areas of the brain and their participation in the performance of certain functions before and after wrist tapping (WT), using the author's method in JME.

\section{Materials and Methods}

The study included 81 subjects of working age, including 51 clinically healthy volunteers (median age of $39[21 ; 56]$ years) and 30 patients (median age of 27[23;38] years) with JME. Analysis of IC in the electrode pairs Fp1Fp2, F3-F4, C3-C4, T3-T4 (Figure 1) was performed using a computer encephalographic complex ("Neurocartograph", MBS, Moscow).

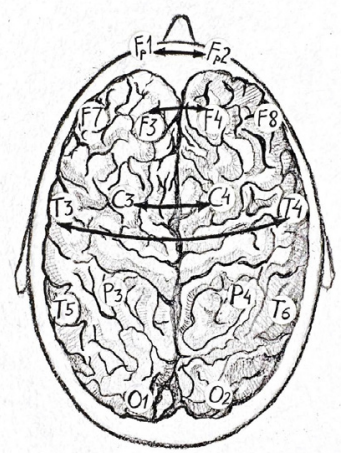

Fig. 1. Pairs of electrodes for evaluating IC: $F 1-F 2$ (frontopolar); $F 3-F 4$ (frontal); $C 3-C 4$ (central); T3-T4 and T5- T6 (temporal).

We used coherent EEG analysis as an accessible neurophysiological technique that allows us to identify and evaluate the relationships between different areas of the brain, since the coherence coefficients (CCs) allow us to detect and evaluate the functional activity and participation of different areas of the cortex in the performance of certain functions. Based on the change in $\mathrm{CCs},{ }^{(5)}$ it becomes possible to quantify the level of integrative activity of brain structures. At the same time, CC, being a measure of coherent EEG analysis, can vary from 0 to 1 : the higher the $\mathrm{CC}$, the more consistent the functional activity and integration of one area of the convexital cortex with another.

The study of the WT was carried out according to the author's modified methodology, "Method of exogenous rhythmic stimulation influence on an individual human rhythm” [RF patent №2606489 of 10.01.2017].

Inclusion criteria for the main group:

-Patients with JME

-Signed voluntary informed consent

-Male and female

-The age period: the youth (males 17-21; females 16-20 years); the first period of middle age (males 22-35 years; females 21-35 years); the second period of middle age (males 36-60 years; females 36-55 years)

-Russian-speaking Europeans

Inclusion criteria in the control group:

-Healthy adults

-Signed voluntary informed consent

-Male and female

-The age period: the youth (males 17-21; females 16-20 years); the first period of middle age (males 22-35 years; females 21-35 years); the second period of middle age (males 36-60 years; females 36-55 years)

-Russian-speaking Europeans

Exclusion criteria:

- Children and adolescents

- Refusal to participate in this study

- Participation in other studies

-Acute and chronic neurological, psychiatric and endocrinological disorders at the time of examination

- Alcohol intake ( 2 or more drinks during the last 2 weeks)

- Use of narcotic drugs at the time of the study and in history

Statistical processing was carried out using the STATISTICA Version 10 (StatSoft, USA). The normality of distribution of continuous variables was tested by ShapiroWilk test. Median (Me), interquartile range (IQR; 25th to 75 th percentiles) were calculated. The Mann-Whitney U-Test was used to compare differences between two independent groups. The Wilcoxon test was used to compare differences between two dependent groups. A value of $P<0.05$ was considered significant.

\section{Results abd Discussion}

When studying the characteristics of IC in healthy volunteers before and after WT, we found a statistically significant decrease in CCs, mainly in the fronto-central parts of the brain. The decrease was most pronounced for highfrequency rhythms, compared to low-frequency rhythms. A comparative characteristic of IC in the beta-1 band (Table 1, Figure 2) indicates a statistically significant decrease in $\mathrm{CC}$ in the antero-posterior direction with a predominance decrease in the fronto-central leads. In particular, we observed a statistically significant decrease in CCs in the pairs Fp1-Fp2, F3-F4, and C3-C4 $(P<0.05)$, while in the pair T3-T4, changes in $\mathrm{CCs}$ were not statistically significant $(P>0.05)$. 
Table 1.

Comparative characteristics of IC in healthy volunteers in the beta1 band

\begin{tabular}{|l|c|c|c|c|c|c|c|}
\hline \multirow{2}{*}{$\begin{array}{c}\text { Pairs of } \\
\text { electrodes }\end{array}$} & \multicolumn{3}{|c|}{ Before tapping } & \multicolumn{3}{c|}{ After tapping } & \multirow{2}{*}{$P$-value } \\
\cline { 2 - 7 } & $\mathrm{Me}$ & $\mathrm{P}_{25}$ & $\mathrm{P}_{75}$ & $\mathrm{Me}$ & $\mathrm{P}_{25}$ & $\mathrm{P}_{75}$ & \\
\hline Fp1 - Fp2 & 0.12 & 0.09 & 0.18 & 0.11 & 0.66 & 0.16 & 0.0006 \\
\hline F3 - F4 & 0.23 & 0.12 & 0.28 & 0.2 & 0.1 & 0.29 & 0.02 \\
\hline C3 - C4 & 0.23 & 0.15 & 0.32 & 0.22 & 0.1 & 0.32 & 0.004 \\
\hline T3 - T4 & 0.05 & 0.03 & 0.07 & 0.04 & 0.03 & 0.06 & 0.056 \\
\hline
\end{tabular}

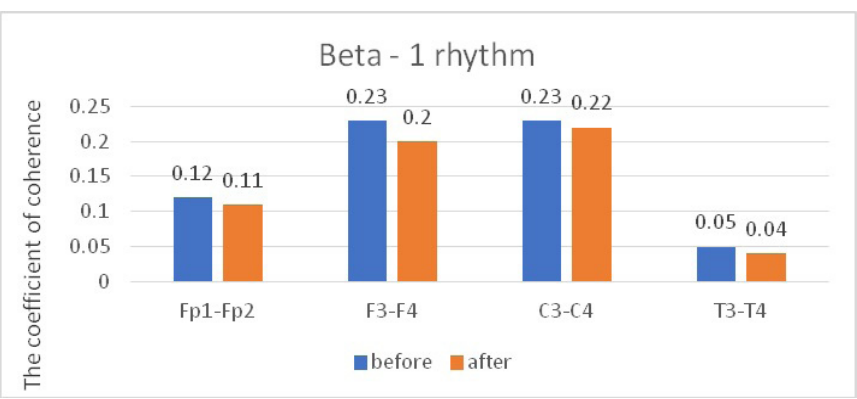

Fig. 2. Main characteristics of IC in healthy volunteers in the beta-1 band: blue column - before WT; orange column-after WT.

Similar dynamics were observed when comparing the characteristics of IC in the alpha band (Table 2, Figure 3). However, the zonal gradient was less pronounced when we analyzed dynamics in the alpha rhythm, compared to the beta1 band. At the same time, a statistically significant decrease in $\mathrm{CCs}$ in the alpha band was found only in the frontal regions in the pairs Fp1-Fp2 and F3-F4 $(P<0.05)$, while changes in $\mathrm{CCs}$ were not statistically significant in the pairs $\mathrm{C} 3-\mathrm{C} 4$ and T3-T4 $(P>0.05)$.

Table 2.

Comparative characteristics of IC in healthy volunteers in the alpha band

\begin{tabular}{|l|c|c|c|c|c|c|c|}
\hline \multirow{2}{*}{$\begin{array}{c}\text { Pairs of } \\
\text { electrodes }\end{array}$} & \multicolumn{3}{|c|}{ Before tapping } & \multicolumn{3}{c|}{ After tapping } & \multirow{2}{*}{ P-value } \\
\cline { 2 - 8 } & $\mathrm{Me}$ & $\mathrm{P}_{25}$ & $\mathrm{P}_{75}$ & $\mathrm{Me}$ & $\mathrm{P}_{25}$ & $\mathrm{P}_{75}$ & \\
\hline Fp1 - Fp2 & 0.29 & 0.17 & 0.41 & 0.25 & 0.11 & 0.4 & 0.001 \\
\hline F3 - F4 & 0.42 & 0.26 & 0.54 & 0.38 & 0.21 & 0.56 & 0.0116 \\
\hline C3 - C4 & 0.44 & 0.28 & 0.52 & 0.39 & 0.25 & 0.54 & 0.13 \\
\hline T3 - T4 & 0.13 & 0.07 & 0.22 & 0.13 & 0.07 & 0.21 & 0.74 \\
\hline
\end{tabular}

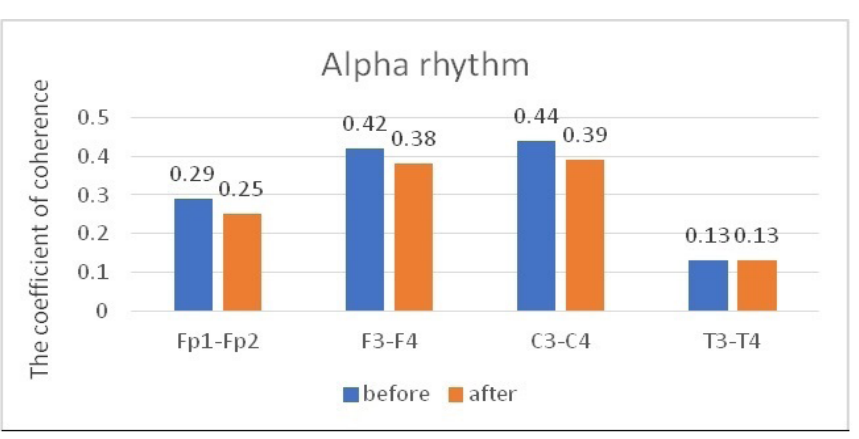

Fig. 3. Main characteristics of IC in healthy volunteers in the alpha band: blue column - before WT; orange column-after WT.
When we analyzed the dynamics of CCs in the theta band, no statistically significant changes were found in all the studied pairs (Table 3, Figure 4).

Table 3.

Comparative characteristics of IC in healthy volunteers in the theta band

\begin{tabular}{|l|c|c|c|c|c|c|c|}
\hline \multirow{2}{*}{$\begin{array}{c}\text { Pairs of } \\
\text { electrodes }\end{array}$} & \multicolumn{3}{|c|}{ Before tapping } & \multicolumn{3}{c|}{ After tapping } & \multirow{2}{*}{-value } \\
\cline { 2 - 7 } & $\mathrm{Me}$ & $\mathrm{P}_{25}$ & $\mathrm{P}_{75}$ & $\mathrm{Me}$ & $\mathrm{P}_{25}$ & $\mathrm{P}_{75}$ & \multirow{2}{*}{ Fp1 - Fp2 } \\
0.12 & 0.07 & 0.18 & 0.1 & 0.008 & 0.25 & 0.09 \\
\hline F3 - F4 & 0.27 & 0.15 & 0.44 & 0.27 & 0.12 & 0.37 & 0.01 \\
\hline C3 - C4 & 0.29 & 0.16 & 0.44 & 0.27 & 0.13 & 0.38 & 0.04 \\
\hline T3 - T4 & 0.07 & 0.04 & 0.14 & 0.07 & 0.04 & 0.11 & 0.138 \\
\hline
\end{tabular}

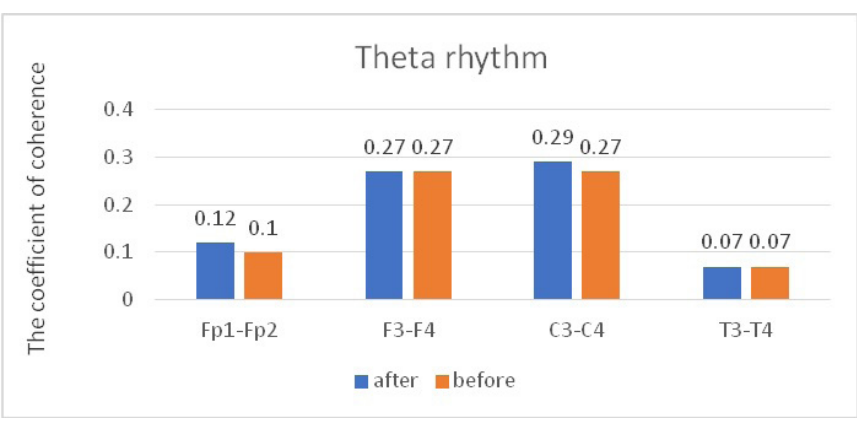

Fig. 4. Main characteristics of IC in healthy volunteers in the theta band: blue column - before WT; orange column-after WT.

When comparing CCs in JME patients in beta- 1 and theta bands, before and after WT, we did not find statistically significant changes in CCs in all the studied electrode pairs (Tables 4, 5; Figures 5, 6). However, in the alpha band, we found a statistically significant decrease in $\mathrm{CCs}$ in the frontal region in the $\mathrm{F} 3-\mathrm{F} 4(P=0.0038)$ and $\mathrm{C} 3-\mathrm{C} 4$ electrode pairs $(P=0.034)$ (Table 6, Figure 7).

Table 4.

Comparative characteristics of IC in JME patients in the beta-1 band

\begin{tabular}{|c|c|c|c|c|c|c|c|}
\hline \multirow{2}{*}{$\begin{array}{l}\text { Pairs of } \\
\text { electrodes }\end{array}$} & \multicolumn{3}{|c|}{ Before tapping } & \multicolumn{3}{|c|}{ After tapping } & \multirow[b]{2}{*}{$P$-value } \\
\hline & $\mathrm{Me}$ & $\mathrm{P}_{25}$ & $\mathrm{P}_{75}$ & $\mathrm{Me}$ & $\mathrm{P}_{25}$ & $\mathrm{P}_{75}$ & \\
\hline Fp1 - Fp2 & 0.255 & 0.15 & 0.46 & 0.27 & 0.17 & 0.41 & 0.753 \\
\hline $\mathrm{F} 3-\mathrm{F} 4$ & 0.4 & 0.31 & 0.58 & 0.455 & 0.27 & 0.61 & 0.775 \\
\hline C3 - C4 & 0.455 & 0.34 & 0.61 & 0.46 & 0.31 & 0.6 & 0.991 \\
\hline $\mathrm{T} 3$ - T4 & 0.18 & 0.14 & 0.24 & 0.175 & 0.11 & 0.25 & 0.592 \\
\hline
\end{tabular}

Table 5.

Comparative characteristics of IC in JME patients in the theta band

\begin{tabular}{|l|c|c|c|c|c|c|c|}
\hline \multirow{2}{*}{$\begin{array}{c}\text { Pairs of } \\
\text { electrodes }\end{array}$} & \multicolumn{3}{|c|}{ Before tapping } & \multicolumn{3}{c|}{ After tapping } & \multirow{2}{*}{} \\
\cline { 2 - 8 } & $\mathrm{Me}$ & $\mathrm{P}_{25}$ & $\mathrm{P}_{75}$ & $\mathrm{Me}$ & $\mathrm{P}_{25}$ & $\mathrm{P}_{75}$ & $P$-value \\
\hline Fp1 - Fp2 & 0.39 & 0.22 & 0.52 & 0.32 & 0.2 & 0.47 & 0.477 \\
\hline F3 - F4 & 0.45 & 0.34 & 0.6 & 0.47 & 0.3 & 0.6 & 0.837 \\
\hline C3 - C4 & 0.47 & 0.32 & 0.61 & 0.44 & 0.32 & 0.64 & 0.573 \\
\hline T3 - T4 & 0.24 & 0.13 & 0.4 & 0.21 & 0.11 & 0.36 & 0.362 \\
\hline
\end{tabular}




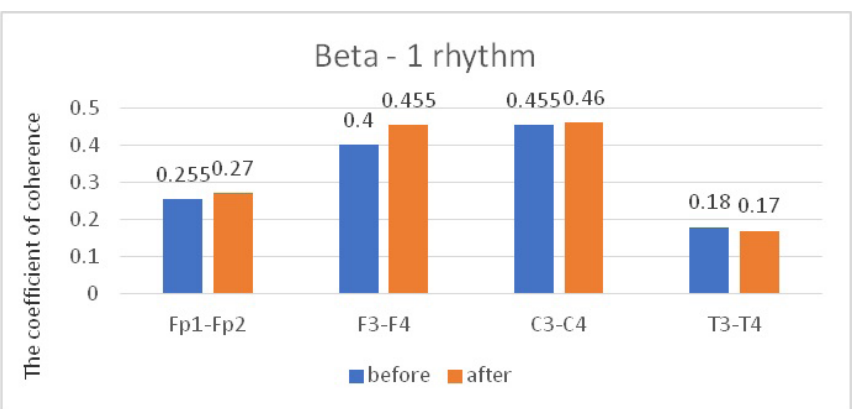

Fig. 5. Main characteristics of IC in JME patients in the beta-1 band: blue column - before WT; orange column-after WT.

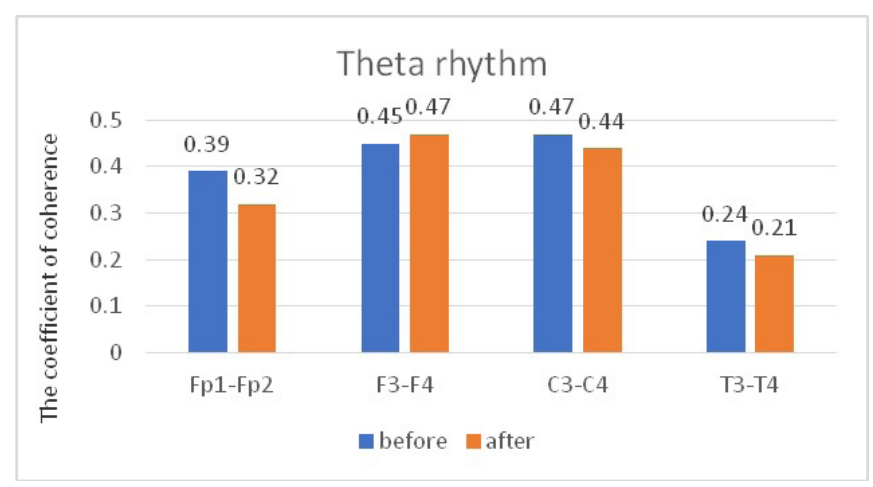

Fig. 6. Main characteristics of IC in JME patients in the theta band: blue column - before WT; orange column-after WT.

Table 6.

Comparative characteristics of IC in JME patients in the alpha band

\begin{tabular}{|l|c|c|c|c|c|c|c|}
\hline \multirow{2}{*}{$\begin{array}{c}\text { Pairs of } \\
\text { electrodes }\end{array}$} & \multicolumn{3}{|c|}{ Before tapping } & \multicolumn{3}{c|}{ After tapping } & \multirow{2}{*}{} \\
\cline { 2 - 7 } & $\mathrm{Me}$ & $\mathrm{P}_{25}$ & $\mathrm{P}_{75}$ & $\mathrm{Me}$ & $\mathrm{P}_{25}$ & $\mathrm{P}_{75}$ & $P$-value \\
\hline Fp1 - Fp2 & 0,51 & 0,43 & 0,61 & 0,45 & 0,35 & 0,57 & 0,17 \\
\hline F3 - F4 & 0,66 & 0,57 & 0,73 & 0,62 & 0,51 & 0,74 & 0,038 \\
\hline C3 - C4 & 0,68 & 0,57 & 0,76 & 0,67 & 0,48 & 0,75 & 0,034 \\
\hline T3 - T4 & 0,41 & 0,22 & 0,47 & 0,32 & 0,18 & 0,49 & 0,158 \\
\hline
\end{tabular}

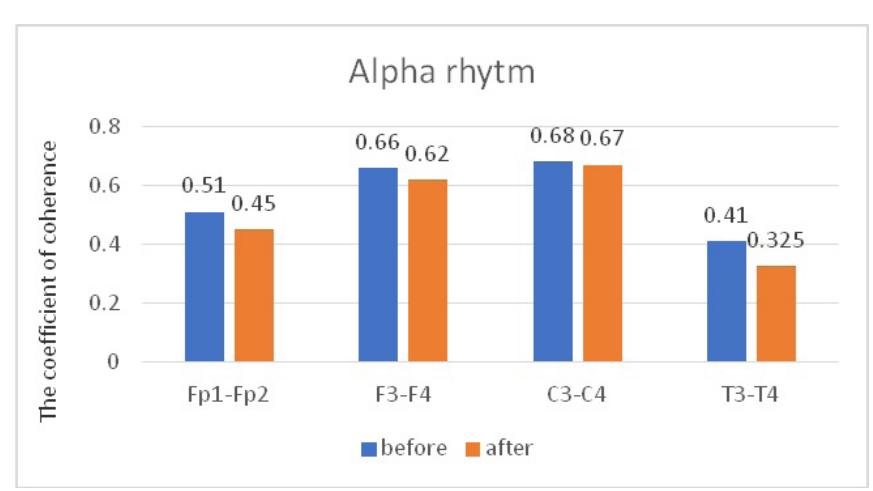

Fig. 7. Main characteristics of IC in JME patients in the alpha band: blue column - before WT; orange column-after WT.

The data we obtained are consistent with the results of studies conducted earlier on healthy volunteers, ${ }^{(6,7)}$ as well as with the results of our studies in the control group of healthy volunteers. After a session of WT according to the author's method, our control group showed a decrease in the strength of correlations between the coefficients of IC, mainly for the beta -1 band and to a lesser extent for the alpha band, in the anterior hemispheres (frontal cortex). In contrast, a comparable group of patients with JME in the interictal period experienced a statistically significant decrease in the strength of correlations between CCs, to a greater extent for the alpha band, as well as in the anterior hemispheres.

However, a comparative analysis of CCs for the beta1 band in JME patients and in the control group showed statistically significant differences in CCs in all studied electrode pairs(Fp1-Fp2, F3-F4, C3-C4, T3-T4), consisting in higher $\mathrm{CC}$ indicators, both before tapping and after tapping in JME patients (Table 7), which may be due to a higher level of synchronization of cortical rhythms in epilepsy than in the norm. It is noteworthy that the greatest statistical significance of intergroup differences was noted in the mid-temporal leads (T3-T4), which is consistent with the results of a neuroradiological study on the involvement of the mediobasal parts of the temporal lobe. ${ }^{(8-10)}$

Table 7.

Comparative characteristics of IC in healthy volunteers and JME patients in the beta-1 band

\begin{tabular}{|c|c|c|c|c|c|c|}
\hline \multirow{2}{*}{ 됭 } & \multicolumn{2}{|c|}{ Before tapping } & \multirow{2}{*}{$\frac{\mathscr{e}}{ٍ]}$} & \multicolumn{2}{|c|}{ After tapping } & \multirow{2}{*}{$\frac{\mathscr{O}}{\frac{\pi}{\pi}}$} \\
\hline & $\begin{array}{c}\mathrm{HV} \\
\mathrm{Me}\left[\mathrm{P}_{25} ; \mathrm{P}_{75}\right]\end{array}$ & $\begin{array}{c}\mathrm{JME} \\
\mathrm{Me}\left[\mathrm{P}_{25} ; \mathrm{P}_{75}\right]\end{array}$ & & $\begin{array}{c}\mathrm{HV} \\
\mathrm{Me}\left[\mathrm{P}_{25} ; \mathrm{P}_{75}\right.\end{array}$ & $\begin{array}{c}\mathrm{JME} \\
\mathrm{Me}\left[\mathrm{P}_{25} ; \mathrm{P}_{75}\right.\end{array}$ & \\
\hline 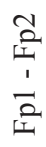 & $\begin{array}{c}0.12 \\
{[0.09 ; 0.18]}\end{array}$ & $\begin{array}{c}0.255 \\
{[0.15 ; 0.46]}\end{array}$ & $\begin{array}{l}\text { ㅇ. } \\
8 \\
8 \\
0 \\
0\end{array}$ & $\begin{array}{c}0.11 \\
{[0.66 ; 0.16]}\end{array}$ & $\begin{array}{c}0.27 \\
{[0.17 ; 0.41]}\end{array}$ & $\begin{array}{l}\text { J } \\
8 \\
8 \\
8 \\
0 \\
0\end{array}$ \\
\hline 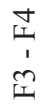 & $\begin{array}{c}0.23 \\
{[0.12 ; 0.28]}\end{array}$ & {$\left[\begin{array}{c}0.4 \\
{[0.31 ; 0.58]}\end{array}\right.$} & 궁 & $\begin{array}{c}0.2 \\
{[0.1 ; 0.29]}\end{array}$ & {$\left[\begin{array}{c}0.45 \\
{[0.27 ; 0.61]}\end{array}\right.$} & 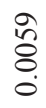 \\
\hline $\begin{array}{l}\text { U } \\
\text { U3 }\end{array}$ & $\begin{array}{c}0.23 \\
{[0.15 ; 0.32]}\end{array}$ & $\begin{array}{c}0.45 \\
{[0.34 ; 0.61]}\end{array}$ & $\begin{array}{l}n \\
8 \\
0\end{array}$ & $\begin{array}{c}0.22 \\
{[0.1 ; 0.32]}\end{array}$ & $\begin{array}{c}0.46 \\
{[0.31 ; 0.6]}\end{array}$ & '̂̊̊ \\
\hline $\begin{array}{l}\stackrel{+}{H} \\
\stackrel{1}{\oplus}\end{array}$ & $\begin{array}{c}0.05 \\
{[0.03 ; 0.07]}\end{array}$ & $\begin{array}{c}0.18 \\
{[0.14 ; 0.24]}\end{array}$ & $\begin{array}{l}8 \\
8 \\
8 \\
0\end{array}$ & $\begin{array}{c}0.04 \\
{[0.03 ; 0.06]}\end{array}$ & $\begin{array}{c}0.17 \\
{[0.1 ; 0.25]}\end{array}$ & $\begin{array}{l}8 \\
8 \\
0\end{array}$ \\
\hline
\end{tabular}

$H V$ - healthy volunteer; PoE-pairs of electrodes

A comparative analysis of the characteristics of IC for alpha rhythm also showed statistically significant differences due to higher values of CCs before and after WT in JME patients, compared to the control group (Table 8), while CCs in both the alpha band and the beta- 1 band have the most significant intergroup differences in the mid-temporal divisions (T3-T4). A similar picture was observed when we compared the characteristics of IC in the theta band (Table 9).

Thus, the results of the study of interhemispheric integration (based on the analysis of IC coefficients in patients with JME during the interictal period of background EEG at rest and after a WT session using the author's method) showed statistically significant differences between patients with JME and the control group. However, the dynamics of CC 
indicators in the JME group, compared to the control group, after a single session of WT according to the author's method was insignificant, which is probably due to the presence of a stable pathological condition in patients with epilepsy - the epileptoic system.

\section{Table 8.}

Comparative characteristics of IC in healthy volunteers and JME patients in the alpha band

\begin{tabular}{|c|c|c|c|c|c|c|}
\hline \multirow{2}{*}{ 넹 } & \multicolumn{2}{|c|}{ Before tapping } & \multirow{2}{*}{$\begin{array}{l}\frac{0}{3} \\
\frac{3}{7} \\
2^{1}\end{array}$} & \multicolumn{2}{|c|}{ After tapping } & $\mathscr{g}$ \\
\hline & $\begin{array}{c}\mathrm{HV} \\
\mathrm{Me}\left[\mathrm{P}_{25} ; \mathrm{P}_{75}\right]\end{array}$ & $\begin{array}{c}\text { JME } \\
\mathrm{Me}\left[\mathrm{P}_{25} ; \mathrm{P}_{75}\right]\end{array}$ & & $\begin{array}{c}\mathrm{HVr} \\
\mathrm{Me}\left[\mathrm{P}_{25} ; \mathrm{P}_{75}\right]\end{array}$ & $\begin{array}{c}\mathrm{JME} \\
\mathrm{Me}\left[\mathrm{P}_{25} ; \mathrm{P}_{75}\right]\end{array}$ & $\sum_{1}^{\pi}$ \\
\hline $\begin{array}{l}\frac{1}{2} \\
\frac{1}{1} \\
\frac{1}{2}\end{array}$ & $\begin{array}{c}0.29 \\
{[0.17 ; 0.41]}\end{array}$ & $\begin{array}{c}0.51 \\
{[0.43 ; 0.61]}\end{array}$ & $\stackrel{\text { ô }}{0}$ & $\begin{array}{c}0.25 \\
{[0.11 ; 0.4]}\end{array}$ & $\begin{array}{c}0.45 \\
{[0.35 ; 0.57]}\end{array}$ & $\begin{array}{l}\text { \&े } \\
\delta \\
0\end{array}$ \\
\hline $\begin{array}{l}\text { I } \\
\text { m } \\
\stackrel{1}{1}\end{array}$ & $\begin{array}{c}0.42 \\
{[0.26 ; 0.54]}\end{array}$ & $\begin{array}{c}0.66 \\
{[0.57 ; 0.73]}\end{array}$ & ণิ & $\begin{array}{c}0.38 \\
{[0.21 ; 0.56]}\end{array}$ & {$\left[\begin{array}{c}0.62 \\
{[0.51 ; 0.74]}\end{array}\right.$} & $\begin{array}{l}\text { पे } \\
0 \\
0\end{array}$ \\
\hline $\begin{array}{l}0 \\
1 \\
0\end{array}$ & $\begin{array}{c}0.44 \\
{[0.28 ; 0.52]}\end{array}$ & $\begin{array}{c}0.68 \\
{[0.57 ; 0.76]}\end{array}$ & $\begin{array}{l}\infty \\
8 \\
8 \\
0 \\
0\end{array}$ & $\begin{array}{c}0.39 \\
{[0.25 ; 0.54]}\end{array}$ & $\begin{array}{c}0.67 \\
{[0.48 ; 0.75]}\end{array}$ & है \\
\hline $\begin{array}{l}\stackrel{+}{\oplus} \\
\stackrel{1}{\oplus}\end{array}$ & $\begin{array}{c}0.13 \\
{[0.07 ; 0.22]}\end{array}$ & $\begin{array}{c}0.41 \\
{[0.22 ; 0.47]}\end{array}$ & $\begin{array}{l}\overline{8} \\
8 \\
0\end{array}$ & $\begin{array}{c}0.13 \\
{[0.07 ; 0.21]}\end{array}$ & {$\left[\begin{array}{c}0.32 \\
{[0.18 ; 0.49]}\end{array}\right.$} & $\begin{array}{l}\overline{8} \\
8 \\
0\end{array}$ \\
\hline
\end{tabular}

$H V$ - healthy volunteer; PoE-pairs of electrodes

\section{Table 9.}

Comparative characteristics of IC in healthy volunteers and JME patients in the theta band

\begin{tabular}{|c|c|c|c|c|c|c|}
\hline \multirow{2}{*}{ 핑 } & \multicolumn{2}{|c|}{ Before tapping } & \multirow{2}{*}{$\begin{array}{l}\frac{\mathscr{O}}{3} \\
\frac{\pi}{\pi} \\
\Omega^{1}\end{array}$} & \multicolumn{2}{|c|}{ After tapping } & \multirow{2}{*}{$\frac{0}{3}$} \\
\hline & $\begin{array}{c}\mathrm{HV} \\
\mathrm{Me}\left[\mathrm{P}_{25} ; \mathrm{P}_{75}\right]\end{array}$ & $\begin{array}{c}\mathrm{JME} \\
\mathrm{Me}\left[\mathrm{P}_{25} ; \mathrm{P}_{75}\right]\end{array}$ & & $\begin{array}{c}\mathrm{HV} \\
\mathrm{Me}\left[\mathrm{P}_{25} ; \mathrm{P}_{75}\right]\end{array}$ & $\begin{array}{c}\mathrm{JME} \\
\mathrm{Me}\left[\mathrm{P}_{25} ; \mathrm{P}_{75}\right]\end{array}$ & \\
\hline $\begin{array}{l}\text { a } \\
\text { 我 } \\
\frac{1}{2}\end{array}$ & $\begin{array}{c}0.12 \\
{[0.07 ; 0.18]}\end{array}$ & $\begin{array}{c}0.39 \\
{[0.22 ; 0.52]}\end{array}$ & $\stackrel{0}{0}$ & {$\left[\begin{array}{c}0.1 \\
{[0.008 ; 0.25]}\end{array}\right.$} & $\begin{array}{c}0.32 \\
{[0.2 ; 0.47]}\end{array}$ & $\stackrel{1}{0}$ \\
\hline $\begin{array}{l}\text { I } \\
\dot{1} \\
\stackrel{I}{1}\end{array}$ & $\begin{array}{c}0.27 \\
{[0.15 ; 0.44]}\end{array}$ & $\begin{array}{c}0.45 \\
{[0.34 ; 0.6]}\end{array}$ & $\stackrel{n}{0}$ & $\begin{array}{c}0.27 \\
{[0.12 ; 0.37]}\end{array}$ & $\begin{array}{c}0.47 \\
{[0.3 ; 0.6]}\end{array}$ & $\begin{array}{l}8 \\
8 \\
\circ\end{array}$ \\
\hline 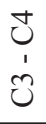 & $\begin{array}{c}0.47 \\
{[0.32 ; 0.61]}\end{array}$ & $\begin{array}{c}0.68 \\
{[0.57 ; 0.76]}\end{array}$ & 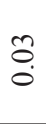 & $\begin{array}{c}0.27 \\
{[0.13 ; 0.38]}\end{array}$ & $\begin{array}{c}0.44 \\
{[0.32 ; 0.64]}\end{array}$ & 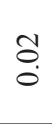 \\
\hline $\begin{array}{l}\stackrel{+}{\oplus} \\
\dot{1} \\
\stackrel{\theta}{H}\end{array}$ & $\begin{array}{c}0.07 \\
{[0.04 ; 0.14]}\end{array}$ & $\begin{array}{c}0.24 \\
{[0.13 ; 0.4]}\end{array}$ & $\begin{array}{l}8 \\
8 \\
\circ\end{array}$ & $\begin{array}{c}0.07 \\
{[0.04 ; 0.11]}\end{array}$ & {$\left[\begin{array}{c}0.21 \\
{[0.11 ; 0.36]}\end{array}\right.$} & ᄋ̊ \\
\hline
\end{tabular}

$H V$ - healthy volunteer; PoE-pairs of electrodes

Thus, this result suggests that in order to obtain a stable antiepileptic effect by activating the neurons of the antiepileptic system, it is necessary to develop and implement not a single, but a course application of wrist tapping. The prospects of this approach are generally confirmed by the positive changes in the state of cortical rhythm under the influence of wrist tapping on the characteristics of the beta-1 and alpha rhythms.

\section{Competing Interests}

The authors declare that they have no competing interests.

\section{References}

1. Bate L, Gardiner M. Molecular genetics of human epilepsies. Expert Rev Mol Med. 1999;1999:1-22. doi: 10.1017/S1462399499001349.

2. Wang L, Wu L, Wang Y, Li H, Liu X, Du X, Dong G. Altered Brain Activities Associated with Craving and Cue Reactivity in People with Internet Gaming Disorder: Evidence from the Comparison with Recreational Internet Game Users. Front Psychol. 2017;8:1150. doi: 10.3389/fpsyg.2017.01150

3. Jiang S, Wen N, Li Z, Dube U, Del Aguila J, Budde J, et al. Integrative system biology analyses of CRISPR-edited iPSC-derived neurons and human brains reveal deficiencies of presynaptic signaling in FTLD and PSP. Transl Psychiatry. 2018;8(1):265. doi: 10.1038/s41398-018-0319-Z

4. Wang Y, Berglund IS, Uppman M, Li TQ. Juvenile myoclonic epilepsy has hyper dynamic functional connectivity in the dorsolateral frontal cortex. Neuroimage Clin. 2019;21:101604. doi: 10.1016/j.nicl.2018.11.014

5. Ivanov LB. State of intra- and interhemispheric integration according to coherent EEG analysis in healthy children and in pathology. Proceedings of the international conference "Clinical neuroscience: neurophysiology, neurology, neurosurgery." 5th Eastern European Conference "Epilepsy and Clinical Neurophysiology." Yalta-Gurzuf, June 01-10, 2003. Gurzuf; 2003:32-35. [in Russian]

6. Kanda PAM, Anghinah R, Smidth MT, Silva JM. The clinical use of quantitative EEG in cognitive disorders. Dement Neuropsychol. 2009;3(3):195-203. doi: 10.1590/ S1980-57642009DN30300004

7. Coan JA, Allen JJ. Frontal EEG asymmetry as a moderator and mediator of emotion. Biol Psychol. 2004;67(1-2):7-49. doi: 10.1016/j.biopsycho.2004.03.002

8. Hattingen E, Lückerath C, Pellikan S, Vronski D, Roth C, Knake S, Kieslich M, Pilatus U. Frontal and thalamic changes of GABA concentration indicate dysfunction of thalamofrontal networks in juvenile myoclonic epilepsy. Epilepsia. 2014;55(7):1030-1037. doi: 10.1111/epi.12656

9. Lin K, Jackowski AP, Carrete H Jr, de Araújo Filho GM, Silva HH, Guaranha MS, Guilhoto LM, Bressan RA, Yacubian EM. Voxel-based morphometry evaluation of patients with photosensitive juvenile myoclonic epilepsy. Epilepsy Res. 2009;86(2-3):138-145. doi: 10.1016/j.eplepsyres.2009.05.016 10. Kim SH, Lim SC, Kim W, Kwon OH, Jeon S, Lee JM, Shon YM. Extrafrontal structural changes in juvenile myoclonic epilepsy: a topographic analysis of combined structural and microstructural brain imaging. Seizure. 2015;30:124-131. doi: 10.1016/j.seizure.2015.06.009 